Original Research Paper

\title{
Effect of the Papaya Latex on the Visibility of Fingerprint
}

\author{
Chantira Boonsri, Pichet Limsuwan and Prathan Buranasiri \\ Department of Physics, King Mongkut's Institute of Technology Ladkrabang, Bangkok, Thailand
}

\author{
Article history \\ Received: 27-04-2020 \\ Revised: 30-06-2020 \\ Accepted: 23-07-2020 \\ Corresponding Author: \\ Chantira Boonsri \\ Department of Physics, King \\ Mongkut's Institute of \\ Technology Ladkrabang, \\ Bangkok, Thailand \\ Email: chantira.boonsri@gmail.com
}

\begin{abstract}
The effect of the papaya latex on the visibility of fingerprint was investigated. The fingerprints of the thumb without and with touching papaya latex for 5 and 10 min were prepared on the glass slides and captured by CMOS camera. The fingerprint images were reconstructed and the transverse intensity profiles were performed. The valley depth and the ridge width for these prepared fingerprints were determined. The results show that the visibility of the fingerprints increased with increasing touching time with papaya latex. It can be concluded that the finger surface needed to be scanned using any fingerprint sensors should be touched with papaya latex for about $10 \mathrm{~min}$ before image scanning to increase the image quality.
\end{abstract}

Keywords: Fingerprint, Biometric Sensors, Papaya Latex, Proteolytic Enzymes

\section{Introduction}

The skin on the palm and fingers of the human hand has the unique property of being corrugated by a pattern of ridges and valleys (also known as furrows) (Yager and Amin, 2004). Figure 1a shows a diagrammatic sectional view of the magnified skin. It consists of two main layers known as epidermis and dermis. The eccrine sweat glands are found in almost every part of the skin and are located in dermis layer. Each one consists of a single tube with the lower end is spirally coiled. Sweat passed from coiled portion through the ducts and onto the surface of the ridge via a pore (Maceo, 2009). The good review on the anatomy of ridge skin has been presented by (Maceo, 2011). The ridge skin has the highest concentration of eccrine glands, $2500-3000 / 2.5 \mathrm{~cm}^{2}$. The number of sweat pores per centimeter along the ridge varies from 9 to 18 (Jain et al., 2006). In a single fingerprint image more than 1400 sweat pores can be found (Tafazoli et al., 2013).

Sweat, moisture and grease on a finger result in fingerprints on surfaces such as glass or metal. Deliberate impression of entire fingerprints can be obtained by ink transferred from the peaks of ridges on the skin to smooth surface such as paper.

Of particular interest are the ridges and valleys at the tips of fingers, known as fingerprints. Figure $1 \mathrm{~b}$ shows a sample of fingerprint and Fig. 1c shows a magnified view of the ridges and valleys of a fingerprint. It is seen in Fig. $1 \mathrm{~b}$ and $1 \mathrm{c}$ that in a fingerprint image, ridges are dark whereas valleys are bright. This is in contrast with real fingerprint in Fig. 1a where ridges are bright and valleys are dark.
Fingerprints are biometric information and have been used for identifying individuals for over a century. The good reviews on security and accuracy of fingerprintbased biometrics have been presented by (Yang et al., 2019; Alshehri et al., 2018; Ivanov and Baras, 2019). Nowadays, most forensic applications accept live-scan digital images acquired by direct sensing the finger surface with a fingerprint sensor based on different techniques such as optical, capacitive, ultrasonic and thermal fingerprint sensors (Alshehri et al., 2018; Song et al., 2017). The problem in fingerprint capture sensors is the poor image quality. The fingerprint quality not only depends on environment such as moisture but also changes over time. There are many different sensing methods to obtain the ridge and valley patterns of finger skin or fingerprint. Therefore, all the developed fingerprint sensors have been tried to improve the visibility of the ridges and the ridge-valley contrast in which the trend is toward compact and low-cost device (Back et al., 2016; Cui et al., 2016; Cheng and Larin, 2006; Nedjah et al., 2019; Ivanov and Baras, 2019).

Papaya, botanical name Carica papaya is an economically important fruit tree of tropical and subtropical lowland countries such as Africa, Asia and the Pacific and South America (Silva et al., 2007). For the immature fruits, the skin of raw papaya fruits is green and it is rich in white latex. The papaya latex is obtained by cutting the skin of the green fruit and then collecting the latex which flow from the cut. The white latex is at first liquid but rapidly forms a gel. 


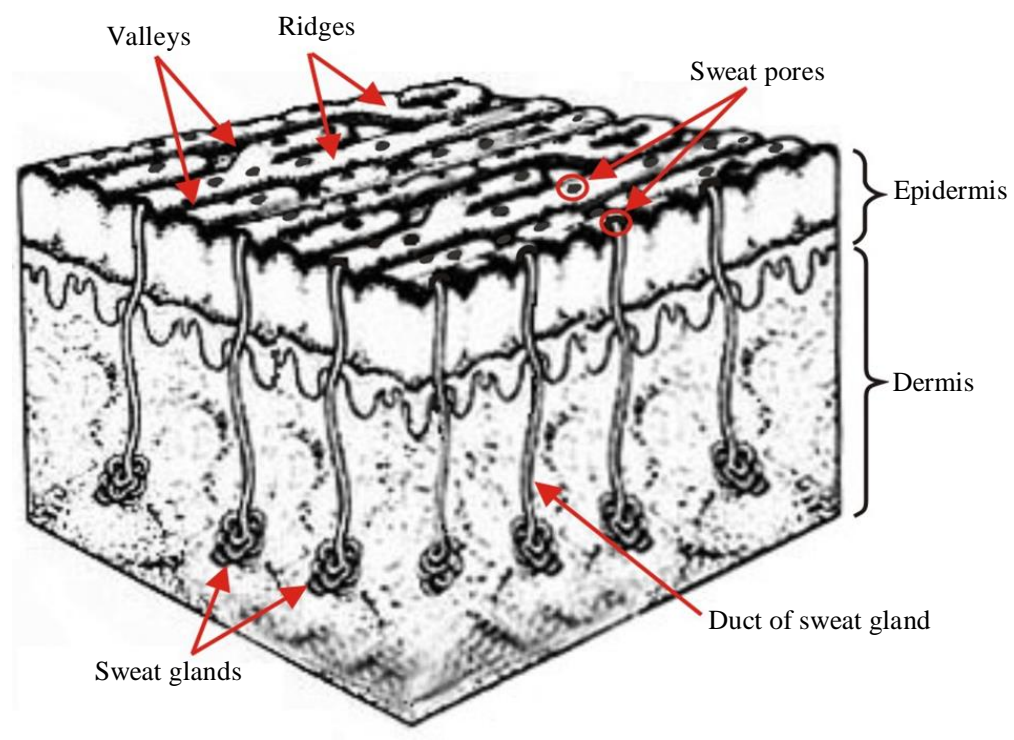

(a)

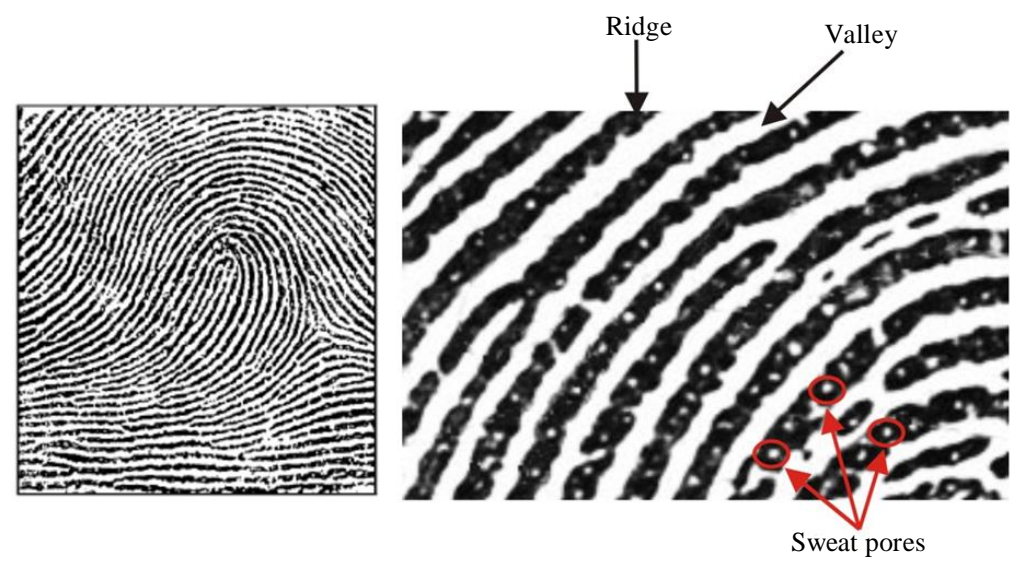

(b)

(c)

Fig. 1: (a) Diagrammatic sectional view of magnified skin (modified from Ref. (Hicklin, 2009), (b) a fingerprint (Yager and Amin, 2004) and (c) a magnified view of fingerprint ridges (Hicklin, 2009)

The raw papaya latex contains many biologically active compounds. Two important compounds are papain (EC 3.4.22.2) and chymopapain (EC 3.4.22.6) which are proteolytic enzymes (Silva et al., 2007; Amri and Mamboya, 2012). Papain has a molecular mass of 23.406 and a 212 aminoacids polypeptide chain. This enzyme is able to break down organic molecules (Amri and Mamboya, 2012). Therefore, the enzyme papain and the extraction process of papain from papaya latex have been extensively studied (Andrade-Mahecha et al., 2011; Thomás et al., 2009; Urgessa et al., 2019; Monti et al., 2000; Azarkan et al., 2003; Aravind et al., 2013).

The papain extracted from papaya latex has found many applications in food, pharmaceutics, cosmetics and textile industries (Thomás et al., 2009). In the food industry it is used as meat tenderizers (Aravind et al., 2013). Recently, it was used for transforming raw trimming waste from tannery to gelatin (Urgessa et al., 2019).

In this study, the papaya latex was prepared and the Right-Hand (RH) thumb was touched with the latex and waited for different times of 5 and $10 \mathrm{~min}$. After each touching time to the papaya latex, the thumb was washed with water to remove the papaya latex. Then, pressing the thumb onto the blue-ink stamper and later on a glass slide. The glass slides with fingerprints of different touching times with papaya latex were used for capturing the fingerprints. The effect of papaya latex on the visibility of the ridges and the ridge contrast were studied. The results were compared with the fingerprints without touching with papaya latex. 


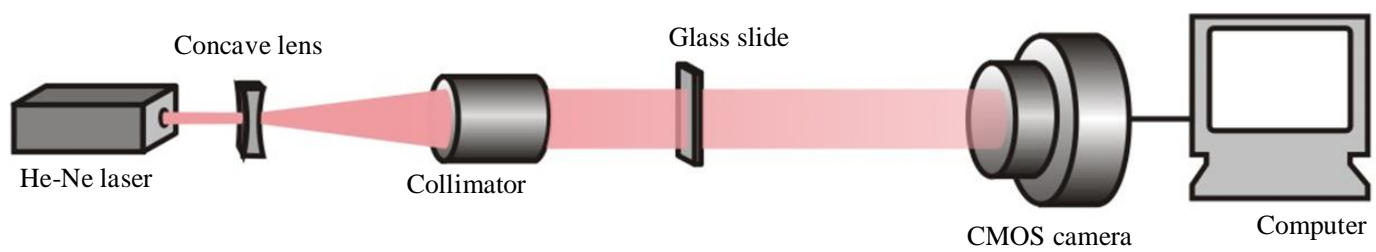

(a)

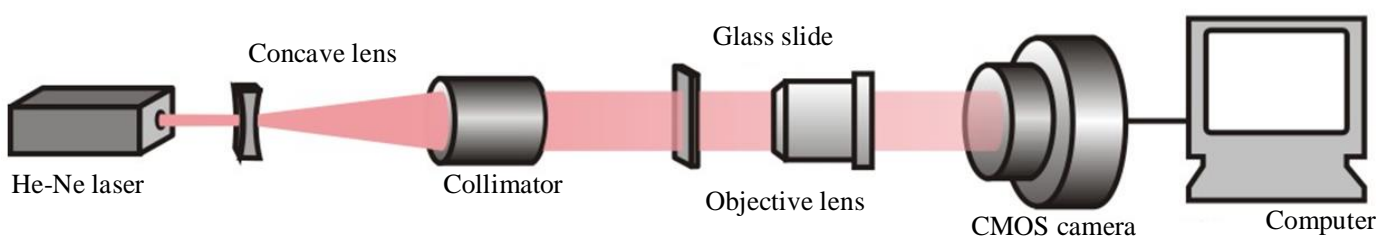

(b)

Fig. 2: Experimental setup for capturing the fingerprints: (a) Without objective lens and (b) with objective lens

\section{Materials and Methods}

\section{Materials}

The material used was 3 to 6 months old unripe 20 fruits of Carica papaya $L$. Each fruit has a thickness between 8 to $12 \mathrm{~cm}$, length between 15 to $20 \mathrm{~cm}$ and weight between 0.8 to $1 \mathrm{~kg}$. The papaya latex was extracted from 4 longitudinal incisions through the papaya skin by a sharp stainless knife. The fresh papaya latex was dropped in a glass dish.

The Right-Hand (RH) thumb was touched with the papaya latex in the glass dish and waited for different times of 5 and $10 \mathrm{~min}$. After each touching time to the papaya latex, the thumb was washed with water to remove the papaya latex out of the thumb. Then, pressing the thumb onto the blue-ink stamper and later on a glass slide of $1 \mathrm{~mm}$ thick and $25 \times 76 \mathrm{~mm}$ in dimension and the fingerprints appeared on the surface of the glass slide. The glass slides with fingerprints of different touching times with papaya latex were used for capturing the fingerprints as shown in Fig. 2a.

\section{Experimental Setup}

Figure 2a shows the experimental setup to capture the fingerprints. The light source was He-Ne laser emitting the red light at a wavelength of $632 \mathrm{~nm}$. The laser beam with a diameter of $1 \mathrm{~mm}$ was expanded by a concave lens and collimated by a collimator to obtain laser beam with a diameter of about $25 \mathrm{~mm}$. The collimated beam passed through the glass slide stamped with the RH thumb. The fingerprints were captured by a CMOS camera and the digital data were numerically reconstructed using HoloViewer program on MATLAB of Michigan Technological University (USA).

\section{Results and Discussion}

Figure 3a shows the fingerprint image of the $\mathrm{RH}$ thumb without touching with papaya latex (non-PL fingerprint). It is seen that the image was defocused. Therefore, it was reconstructed using HoloViewer program on MATLAB and the reconstructed image was obtained as shown in Fig. 3b.

It can be observed that the visibility of fingerprints was improved after reconstruction. To investigate the width of the ridge and the depth of the valley, the transverse intensity profile was performed in the range corresponding to the yellow line in Fig. 3b. Figure 3c shows the transverse intensity profile of reconstructed fingerprint image. From Fig. 3c, we marked the position of the peaks (i.e. the ridges) as denoted by numbers 1,2 , $3, \ldots, 14$. The width $(w)$ between two neighboring ridges was determined at the position of half maximum width of the peaks using the distance function whereas the depth (d) of the valley was determined directly from the intensity profile. Therefore, the depth of the valley was determined in terms of the intensity with arbitrary unit. The values of width (w), depth (d) and the distance between two neighboring ridges (i.e., peak to peak distance) are given in Table 1.

Figure 4a-5a shows the fingerprint images of the RH thumb touching with papaya latex for 5 and $10 \mathrm{~min}$ and denoted as $5 \mathrm{~min}-\mathrm{PL}$ and $10 \mathrm{~min}-\mathrm{PL}$ fingerprints, respectively. The reconstructed images and transverse intensity profiles were also carried out and the results are shown in Fig. 4b-5b and Fig. 4c-5c, respectively. From the transverse intensity profiles, the ridge width, the valley depth of all peaks of transverse intensity profile and peak to peak distance were determined and the values are also given in Table 1. 


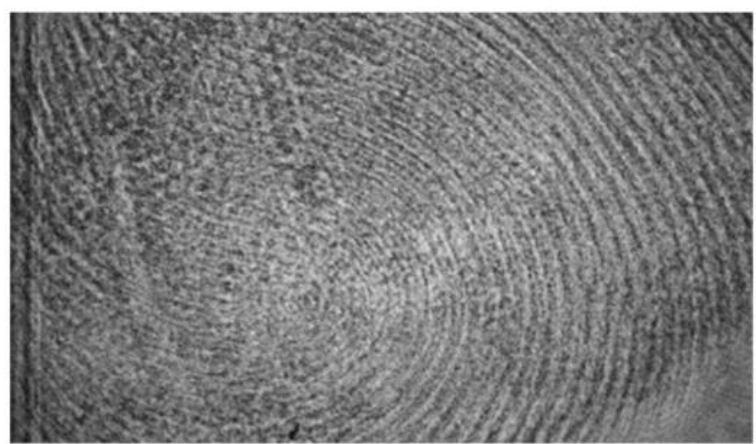

(a)

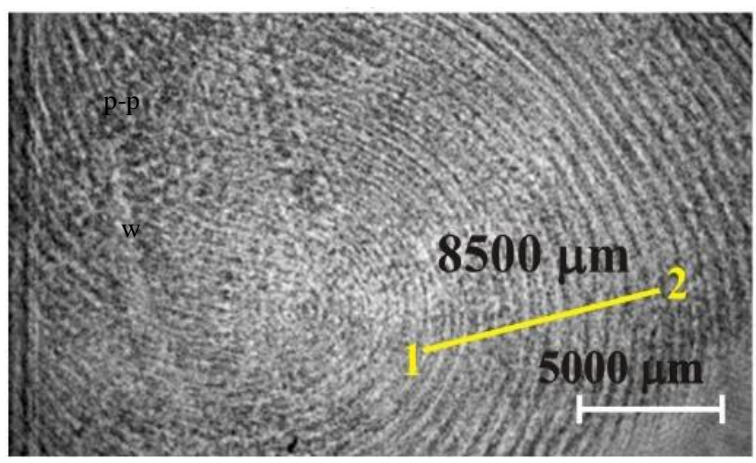

(b)



(c)

Fig. 3: (a) Fingerprint image of RH thumb, (b) reconstructed image and (c) transverse intensity profile of non-PL fingerprint

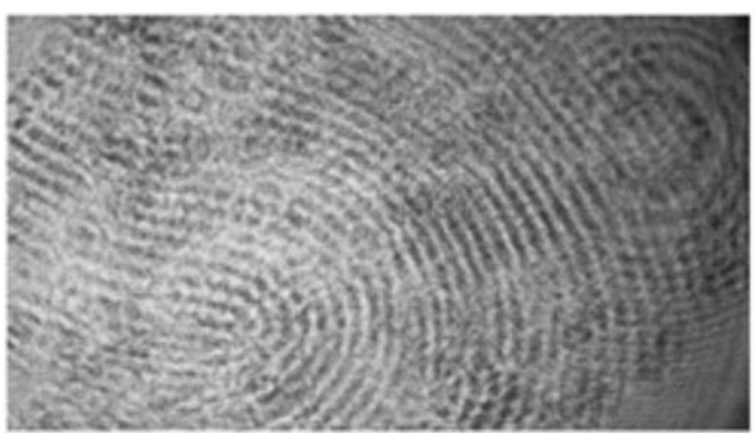

(a) 


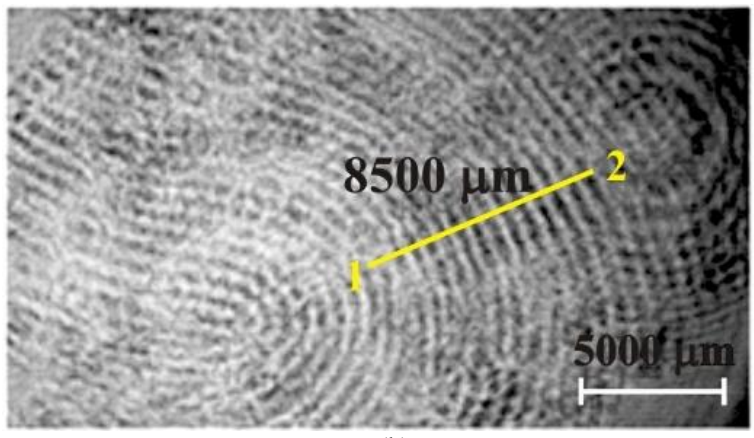

(b)

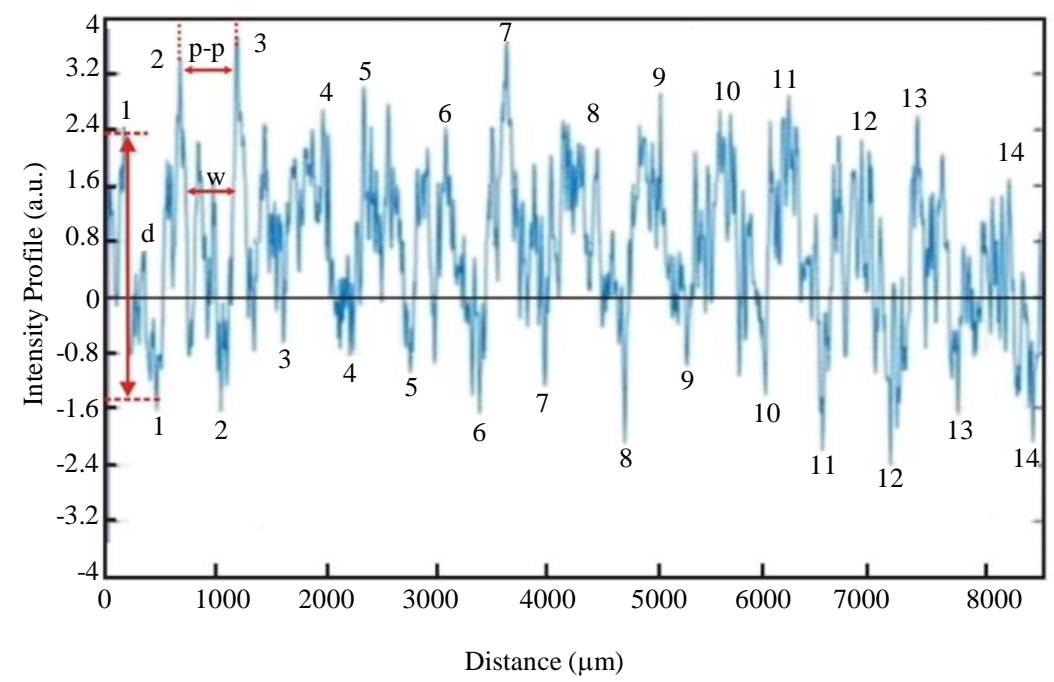

(c)

Fig. 4: (a) Fingerprint image of RH thumb, (b) reconstructed image and (c) transverse intensity profile of 5 min-PL fingerprint

From the values of the valley depth and the ridge width in Table 1, the average valley depth and the average ridge width for non-PL, 5 min-PL and $10 \mathrm{~min}$ PL fingerprints were found to be 2.69, 4.07 and 4.54 and 206, 268 and 311, respectively. It is seen that the ridge width and the valley depth increase with increasing time of touching RH thumb with papaya latex. This result in the increase of ridge-valley contrast and visibility of the ridges as seen from Fig. $3 \mathrm{~b}, 4 \mathrm{~b}$ and $5 \mathrm{~b}$ for non-PL, 5 min-PL and 10 min-PL fingerprints, respectively. As mentioned in the introduction section that the papaya latex consists of enzyme papain that can break down organic molecules. The sweat and grease generally appear on the fingertip surface. When the fingertip is touched with the papaya latex for a few minutes, the sweat and grease can be removed by the papaya latex. After washing the fingertip by water and pressing onto the blue-ink stamper and finally on a glass slide to observe the fingerprints. The longer touching time of finger with papaya latex the wider the ridge width and the deeper the valley depth were observed. Therefore, the fingerprint image of 10 min-PL fingerprint as shown in Fig. 5 shows the highest ridge-valley contrast and an average maximum ridge width of $311 \mu \mathrm{m}$ comparing with $206 \mu \mathrm{m}$ for non-PL fingerprint.

From Table 1, the average peak to peak (p-p) values for non-PL, $5 \mathrm{~min}-\mathrm{PL}$ and $10 \mathrm{~min}-\mathrm{PL}$ fingerprints were found to be 615,632 and 619 in terms of the intensity with arbitrary unit (a.u.). These values are about the same as it should be, since the distance from peak to peak of the ridges must be constant even though the fingertip was not touched with papaya latex and touched with papaya latex for 5 and $10 \mathrm{~min}$.

To confirm that the visibility of the ridges increased with increasing touching time of the thumb with papaya latex, further experiment was carried out on the glass slide with 10 min-PL fingerprint by adding a $4 \mathrm{X}$ achromat microscope objective lens in the laser light path of Fig. 2a. Figure $2 \mathrm{~b}$ shows the experiment setup for observing the magnified image of $10 \mathrm{~min}$-PL fingerprint. Figure $6 \mathrm{a}$ shows the magnified fingerprint image of the RH thumb touching with papaya latex for $10 \mathrm{~min}$. It is seen that the ridges with the pores along the ridges are clearly observed. 


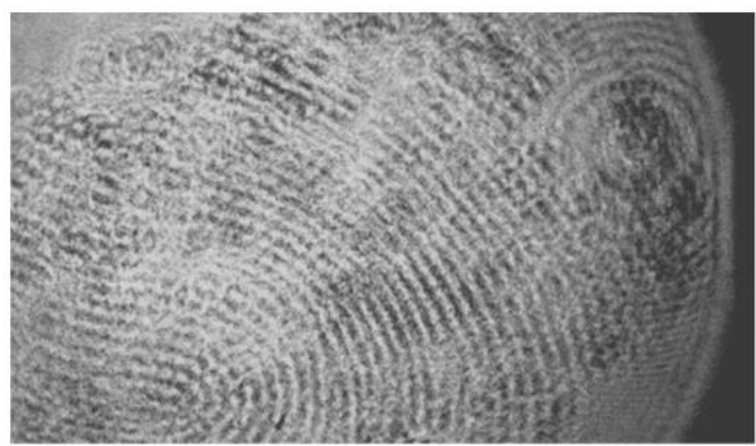

(a)

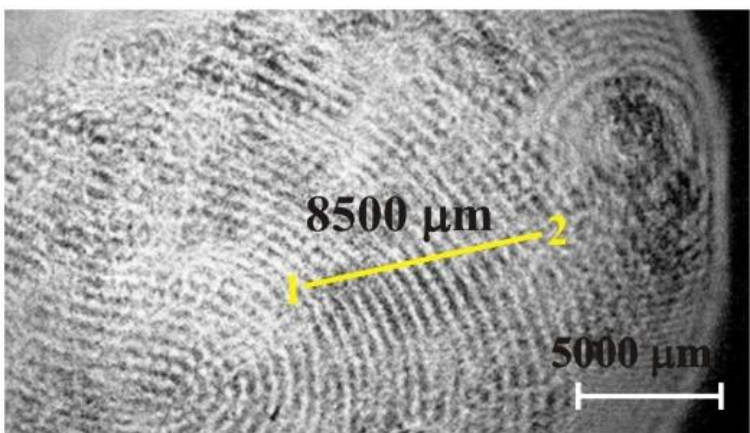

(b)

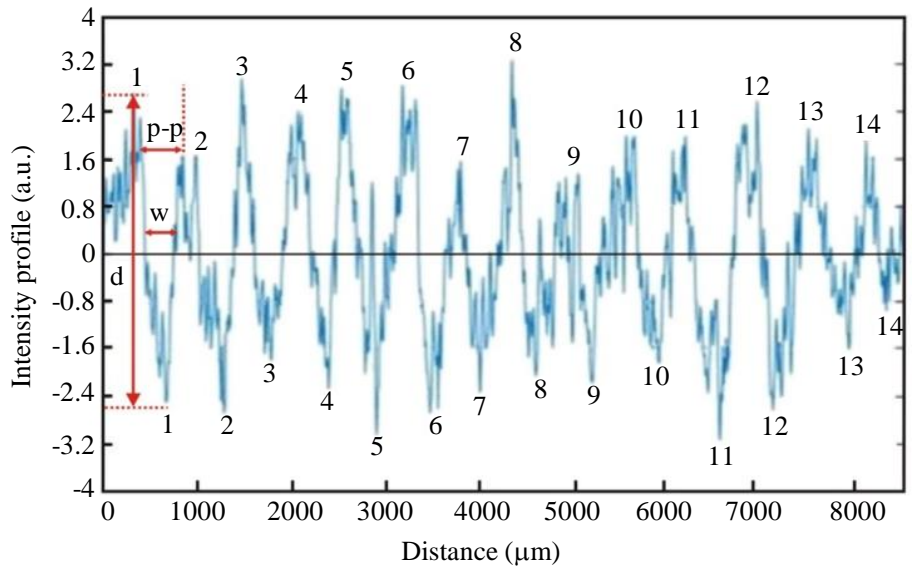

(c)

Fig. 5: (a) Fingerprint image of the RH thumb, (b) reconstructed image and (c) transverse intensity profile of 10 min-PL fingerprint

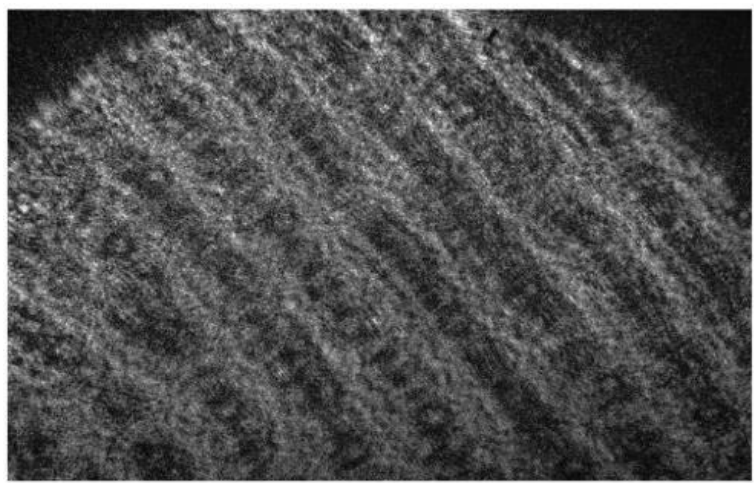

(a) 


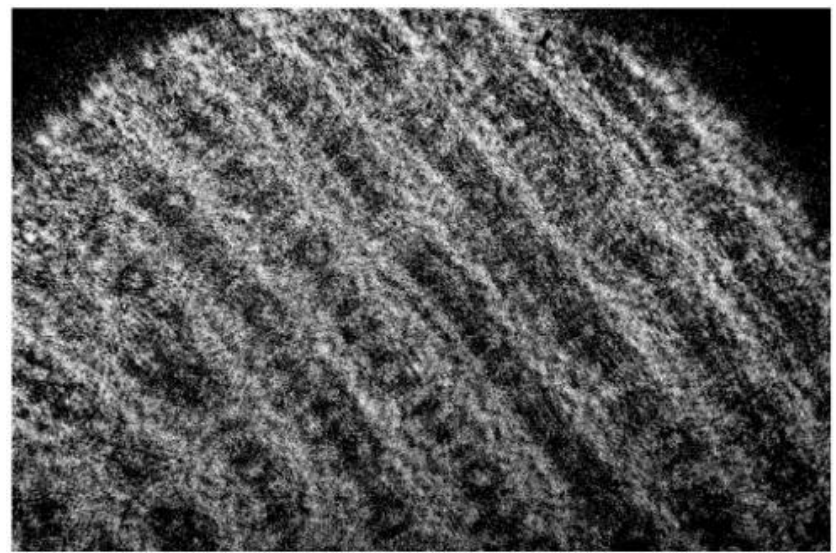

(b)

Fig. 6: (a) Magnified fingerprint image of the RH thumb and (b) reconstructed image of 10 min-PL fingerprint

Table 1: Valley depth (d) in terms of the intensity, ridge width (w) and peak to peak (p-p) of non-PL, 5 min- PL and 10 min-PL fingerprints

\begin{tabular}{|c|c|c|c|c|c|c|c|c|c|}
\hline \multirow[b]{2}{*}{ Distance Positiona } & \multicolumn{3}{|l|}{ Non-PL } & \multicolumn{3}{|l|}{5 min-PL } & \multicolumn{3}{|l|}{10 min-PL } \\
\hline & Intensity (a.u.) & $\mathrm{w}(\mu \mathrm{m})$ & $\mathrm{p}-\mathrm{p}(\mu \mathrm{m})$ & Intensity(a.u.) & $\mathrm{w}(\mu \mathrm{m})$ & $\mathrm{p}-\mathrm{p}(\mu \mathrm{m})$ & Intensity(a.u.) & $\mathrm{w}(\mu \mathrm{m})$ & $\mathrm{p}-\mathrm{p}(\mu \mathrm{m})$ \\
\hline $1-2$ & 0.80 & 255 & 638 & 3.83 & 340 & 851 & 5.22 & 255 & 553 \\
\hline $2-3$ & 2.32 & 170 & 511 & 4.24 & 213 & 426 & 4.24 & 340 & 596 \\
\hline $3-4$ & 2.45 & 128 & 511 & 4.30 & 298 & 766 & 4.73 & 340 & 638 \\
\hline $4-5$ & 2.80 & 255 & 681 & 3.54 & 298 & 553 & 4.66 & 213 & 511 \\
\hline $5-6$ & 1.40 & 85 & 511 & 4.48 & 128 & 511 & 5.85 & 340 & 596 \\
\hline $6-7$ & 2.27 & 255 & 511 & 3.80 & 255 & 468 & 5.53 & 255 & 553 \\
\hline $7-8$ & 3.25 & 128 & 851 & 3.88 & 298 & 723 & 3.88 & 340 & 553 \\
\hline $8-9$ & 3.15 & 213 & 638 & 3.66 & 255 & 766 & 5.33 & 298 & 638 \\
\hline $9-10$ & 2.82 & 255 & 596 & 4.30 & 298 & 681 & 3.40 & 340 & 766 \\
\hline $10-11$ & 3.41 & 213 & 596 & 4.45 & 298 & 596 & 3.80 & 255 & 596 \\
\hline $11-12$ & 3.77 & 170 & 681 & 5.00 & 213 & 638 & 5.14 & 383 & 681 \\
\hline $12-13$ & 3.22 & 170 & 511 & 3.38 & 298 & 553 & 5.21 & 298 & 851 \\
\hline $13-14$ & 3.29 & 383 & 766 & 4.02 & 298 & 681 & 3.73 & 383 & 511 \\
\hline
\end{tabular}

\section{Conclusion}

The effect of the papaya latex on the visibility of fingerprint was investigated. The fingerprints of the $\mathrm{RH}$ thumb without touching papaya latex and with touching papaya latex for 5 and 10 min were prepared on the glass slides. Then, the fingerprints were captured by CMOS camera under the collimated $\mathrm{He}-\mathrm{Ne}$ laser light. The fingerprint images were reconstructed and the transverse intensity profiles were performed. The valley depth and the ridge width for non-PL, $5 \mathrm{~min}-\mathrm{PL}$ and $10 \mathrm{~min}-\mathrm{PL}$ fingerprints were determined. The obtained results show that the ridge-valley contrast of the fingerprints increased with increasing touching time with papaya latex. This confirms that the papaya latex can enhance the visibility of fingerprints. It can be concluded that by touching the finger surface before fingerprint scanning using any fingerprint sensors, the quality of the fingerprint image was increased.

\section{Acknowledgement}

Chantira Boonsri would like to thank Department of Physics, Faculty of Science, King Mongkut's Institute of Technology Ladkrabang for providing all facilities to make this work complete.

\section{Funding}

This work was financially supported by Department of Physics, King Mongkut's Institute of Technology Ladkrabang

\section{Authors Contributions}

Chantira Boonsri: Setup and carried out the experiment, collected all the measurement data and prepared the original manuscript. 
Pichet Limsuwan: Helped in writing the manuscript,

Prathan Buranasiri: Read and approved the manuscript.

\section{Conflicts of Interest}

There are no conflicts of interest on this article for the authors.

\section{Ethical Approval}

This article does not contain any work with human participants or animals.

\section{References}

Alshehri, H., Hussain, M., AboAlSamh, H., \& AlZuair, M. (2018). A large-scale study of fingerprint matching systems for sensor interoperability problem. Sensors, 18(4), 1008.

Amri, E. and Mamboya. F. (2012). Papain, A plant enzyme of biological importance: A Review, American Journal of Biochemistry and Biotechnology, 8 (2), 99-104.

Andrade-Mahecha, M. M., Morales-Rodríguez, O., \& Martínez-Correa, H. A. (2011). Study of the extraction process of papain from the latex of the fruit of papaya (Carica papaya L.) cv. Maradol. Acta Agronómica, 60(3), 218-224.

Aravind, G., Bhowmik, D., Duraivel, S., \& Harish, G. (2013). Traditional and medicinal uses of Carica papaya. Journal of Medicinal Plants Studies, 1(1), 7-15.

Azarkan, M., El Moussaoui, A., Van Wuytswinkel, D., Dehon, G., \& Looze, Y. (2003). Fractionation and purification of the enzymes stored in the latex of Carica papaya. Journal of Chromatography B, 790(1-2), 229-238.

Back, S. W., Lee, Y. G., Lee, S. S., \& Son, G. S. (2016). Moisture-insensitive optical fingerprint scanner based on polarization resolved in-finger scattered light. Optics express, 24(17), 19195-19202.

Cheng, Y., \& Larin, K. V. (2006). Artificial fingerprint recognition by using optical coherence tomography with autocorrelation analysis. Applied optics, 45(36), 9238-9245.

Cui, X., Ma, P., Cao, W., Zheng, J., Kang, P., \& Ye, Z. (2016). Transparent optical fingerprint capture system based on subwavelength metallic grating couplers. Optical Materials Express, 6(12), 3899-3907.

Hicklin, R. A. (2009). Anatomy of Friction Ridge Skin.

Ivanov, V. I., \& Baras, J. S. (2019). Authentication of area fingerprint scanners. Pattern Recognition, 94, 230-249.
Jain, A. K., Chen, Y., \& Demirkus, M. (2006). Pores and ridges: High-resolution fingerprint matching using level 3 features. IEEE transactions on pattern analysis and machine intelligence, 29(1), 15-27.

Maceo, A. V. (2009). Friction ridge skin: Morphogenesis and overview. Wiley Encyclopedia of Forensic Science.

Maceo, A. V. (2011). Anatomy and physiology of adult friction ridge skin. The fingerprint sourcebook, 2-26.

Monti, R., Basilio, C. A., Trevisan, H. C., \& Contiero, J. (2000). Purification of papain from fresh latex of Carica papaya. Brazilian Archives of Biology and Technology, 43(5), 501-507.

Nedjah, N., Wyant, R. S., Mourelle, L. M., \& Gupta, B. B. (2019). Efficient fingerprint matching on smart cards for high security and privacy in smart systems. Information Sciences, 479, 622-639.

Silva, J. D., Rashid, Z., Nhut, D. T., Sivakumar, D., Gera, A., Souza, M. T., \& Tennant, P. (2007). Papaya (Carica papaya L.) biology and biotechnology. Tree and Forestry Science and Biotechnology, 1(1), 47-73.

Song, K. H., Choi, J., \& Chun, J. H. (2017). A Method for Enhancing the Sensing Distance of a Fingerprint Sensor. Sensors, 17(10), 2280.

Tafazoli, M., Mahdavi Shahri, N., Ejtehadi, H., Haddad, F., Jabbari Nooghabi, H., Mahdavi Shahri, M., \& Naderi, S. (2013). Biological variability of sweat gland pores in the fingerprints of a Fars Iranian family from Khorasan Razavi province, Iran. Anatomical Sciences Journal, 10(2), 99-104.

Thomás, G. E., Rodolfo, H. G., Juan, M. D., Georgina, S. F., Luis, C. G., Ingrid, R. B., \& Santiago, G. T. (2009). Proteolytic activity in enzymatic extracts from Carica papaya L. cv. Maradol harvest byproducts. Process biochemistry, 44(1), 77-82.

Urgessa, O. E., Itana, D. D., \& Raga, T. O. (2019). Extraction of Papain from Papaya (Carica papaya L.) Fruit Latex and Its Application in Transforming Tannery Raw Trimming. Ethiopian Journal of Sciences and Sustainable Development, 6(2), 22-32.

Yager, N., \& Amin, A. (2004). Fingerprint verification based on minutiae features: A review. Pattern Analysis and Applications, 7(1), 94-113.

Yang, W., Wang, S., Hu, J., Zheng, G., \& Valli, C. (2019). Security and accuracy of fingerprint-based biometrics: A review. Symmetry, 11(2), 141. 